\title{
The Relationship between the Consumer Credit and the Expected Income Based on the Theory of Adaptive Expectation
}

\author{
Hu Yili* \\ Yunnan University of Finance \& Economics \\ Kunming, China \\ 495920873@qq.com
}

\author{
Li Yuanyuan \\ Yunnan University of Finance \& Economics \\ Kunming, China \\ 495920873@qq.com
}

\begin{abstract}
Although the development of Chinese consumer credit is very fast, the development of consumer credit is not optimistic due to the expectations of residents. There is still a big gap with western countries. The study of the relationship between consumer credit and expected income has important practical significance. This paper first briefly presents the related theories of consumer credit, expected income, and the relationship between consumer credit and expected income, analyzes the growth situations of consumer credit and expected income of Chinese urban residents. Using ADF test, co-integration test and Granger causality test this paper empirically analyzes the relationship between consumer credit and expected income. The results show that the expected income affects the consumer credit. According to the results, some suggestions are put forward, such as increasing the urban residents' income and innovating consumer credit.
\end{abstract}

Keywords-consumer credit; expected income; adaptive expectation

\section{INTRODUCTION}

The essence of consumer credit is the consumer's future income in advance to the spot, i.e., to increase the current income and achieve the expected consumer demand early. If the current consumption expenditure is not enough, consumers can apply consumer credit from financial institutions according to their own expectations of the future permanent income. By means of consumer credit, the borrower's future income will be converted into a real income which they can consume in advance.

Although the Chinese government encourages the development of consumer credit policy, the development of consumer credit in reality is not satisfactory. By the end of 1997, Chinese consumer credit scale was only 17.2 billion Yuan, after a series of reform measures, up to 2015, although Chinese consumer credit balance reached 19 trillion Yuan, but $75 \%$ of the consumer credit is a housing loan, that is, in addition to housing loans, other types of consumer credit are not generally accepted by residents. In addition, in recent years, the proportion of domestic consumer credit is only $20 \%$ in the credit balance, and a big gap exsits compared to western countries. (Data sources: China industry development research network)

Current research of consumer credit mainly focuses on the literature study on risk, regulation, and economic development, the research on the co-relation between consumer credit and expected income of the residents is still lack. Based on the results of literature research and empirical analysis, this paper demonstrates the relationship between consumer credit and expected income of urban residents in China. The author discusses how the changing of urban residents' expected income will affect the change of consumer credit. Based on the results of this study, the paper puts forward the suggestion to promote the urban residents' consumer credit, in order to stimulate consumption and drive economic growth.

The structure of the content is as follows: the second part will review the theories of consumer credit and expected income; the third part mainly introduces the research methods; the fourth part describes the characteristics of data; the fifth part makes an empirical study on the relationship between the consumer credit and expected income of urban residents; the last part draws the conclusion and puts forward some recommendations.

\section{LITERATURE REVIEW}

Marx particularly stressed the function of consumer credit by saying "according to the society scale, the credit system only can make turnover changed under accelerating production and consumption." The more market economy developed, the greater guidance and pulling power of consumer demand made. Philip A. Klein (1976) studied the consumer credit and GNP data of United States after World War II. As the initial development scale of consumer credit is not large, the total consumer credit balance and installment credit generally fell behind the economic growth. After World War II, the consumer credit and macroeconomic cycle showed very strong consistency. The research on consumer credit development by Allen and Gale (2000) used a model analysis on the relationship between

*Corresponding author 
consumer credit and financial assets. They found out that low interest rates and intermediary are the causes of the surge demand in credit, and also will lead to asset bubbles.

He (2002) explained the evidences of consumer credit development on the basis of Marx and Keynes's consumption theory. He said the development of consumer credit conformed to the times trend from the macro point of view. Chinese economic system reform provided a favorable external environment for the development of consumer credit, the development of consumer credit had a great influence to the change of the traditional consumption concept and development of the commercial bank as well as narrowing the gap between rich and poor. The research made by Zhang and Sun (2004) have shown that the expansion of consumer credit makes monetary policy more effective on the alleviation of economic fluctuations, and it can promote economic growth simultaneously [2]. The efficiency of monetary policy transmission is improved by consumer credit through widening interest rate and credit channels, then the role of monetary policy in macroeconomic regulation is further improved.

Pan, Liu (2011) studied the relationship between consumer credit and financial development [7]. He chose Mckinnon index to measure the level of financial development, and then he found out that there is a long-term equilibrium relationship between consumer credit and financial development, and consumer credit has a significant influence on financial development while the latter has a weaker influence on the former. For this reason, he suggested that a guarantee or insurance to the lender in the consumer credit can promote the sustainable development in the financial industry. Guo and Liu (2014) studied the factors of people's consumer credit decisions [8]. They chose the monthly data of loan rate, inflation rate, real estate price level and long-term consumer credit level in 2007 and 2008 for empirical analysis, and found out that the credit interest rate was the main reason affecting the consumer credit, the rise in inflation had little effect on consumer credit, and although the real estate price was related to consumer credit, but this effect was very weak.

The people will make different expectations on the changing trend of the market prices, and appropriate economic decisions will be made based on such expectations to maximize the economic benefits or utility[10]. In the evolution on the expected theory, static expectations, extrapolated expectations, adaptive expectations and rational expectations are presented consequently. Many economists prefer rational expectations, but in recent years, relevant research on rational expectations management may yet to be improved. Firstly, rational expectations theory assumes all the people are completely rational, which is a deviation with the reality. In the market economy, as the influence of psychological and social factors (Thaler, 1980), behaviors of the people generally are only limited rational, especially in the information era, people are more likely affected by the outside information. Secondly, in the rational expectations, the market mechanism can manage without intervention from the government, which is also a bit running away from the reality. "At present, due to the rapid flow of information, the cause of the macroeconomic fluctuation is not completely fundamental factors, the influence of investors' expectation play an increasingly important role" [7].

Therefore, the central bank should guide the investors' behaviors initiative with adaptive expectations management.

People will anticipate the future inflation rate according to the previous inflation rate, and then adjust the wages, so that their real wages do not fall due to inflation. According to the basis of adaptive expectation, Zhu (2003) assumed the current expected income was the sum of errors caused by the deviation between actual income and expected income. He took Xinjiang urban residents as the research object, combined the time series data and cross-sectional data from 1995 to 2000, concluded that the expected income have a great impact on consumer spending, and the actual current income have a decisive effect on the current expected income. Hang, Shen (2004) [6] proposed that in the general condition, when consumers' expected income is relatively higher than the current income, the current spending may increase, but this view has not been empirically verified[6]. Wang (2014) pointed out that with the reform of the distribution system in China, the fixed income of urban residents increased slowly, while the temporary income changed greatly[10]. Therefore, the residents have to combine fixed income and temporary income to predict future income in a certain period, which is the expected income. The great change of Chinese employment system and social security system takes a great impact on the residents' expected income, but also brings uncertainty to the expected income. In addition, she pointed out that if macroeconomic conditions changed from inflation to deflation, people would adjust their income expectations. If the resident' expected income decline, it will inhibit economic growth. On the contrary, if the income of residents is expected to rise, it will promote economic growth.

Flavin (1981), Daly and Hadjimatheou (1981), Hall and Mishki.n (1982) found that consumption react too strongly to the expected income changes. There is an "excessive sensitivity". Campell and Deaton (1989) found that the reaction of consumption is too weak for a future income changes, and that is an "Excess Smooth". Ayaydin and Mehmet (2010) took the structure of income and consumption as a crucial factor which affects the consumer credit. They focused on the consumption behavior of American families, and found that income, consumption structure as well as consumption behavior are the primary factors for selecting or excluding clients by the consumer credit institutions.

Chen Min and Liu (2003) chose the consumer credit data of the United States from 1960 to 1995 to build an econometric model and pointed out that consumer credit was a leading indicator for a macro-economy[6]. Consumer credit reflects a consumer's consumption of the future income in advance. Beaton (2009) argued that the way of using macroeconomic variables, such as growth rate in credit, 
is not appropriate to represent the credit constraint which consumers face[2]. The reason is that the increase or decrease in the expected income results in a reverse effect on the credit requirements. Chinese residents' income channel is single, so that the expected income is basically unchanged. Qian (2015) [5] proposed that there are two preconditions for the popularization and development of consumer credit[9]. The first is that consumers' current income is far greater than the current expenditure, and they have ability to pay credit. The other is that consumers' expected income can be managed to be higher than the current income. At least one of the above conditions be met, consumer credit could be developed.

Based on the above literature, most believe that consumer credit is related to expected income. However, there is no specific research on the relationship between consumer credit and expected income based on different expectations. This paper puts forward the assumption that there is a relative relationship between the consumer credit and expected income of urban residents in China based on the adaptive expectations.

\section{RESEARCH METHODS}

According to the adaptive expectation theory, this paper assumes that the expected income of the residents is equal to the current income. In order to testify the assumption, the researchers did the pilot study. In the early stage of the study, a case study of consumer credit in two commercial banks has been carried out. There are four typical cases: Civil servant A needed to buy a car for home use which is worth 300,000 RMB. According to A's current family economic strength, he cannot make a lump sum payment, so he applied for a 3year 200,000 RMB car loan from the commercial bank D. The bank examined the A's relevant information. A's annual income is about $90,000 \mathrm{RMB}$, he does not have history of default, and his marital status is married. His wife is a worker in a state-owned company, her annual income is about 90,000 RMB. The bank thought A has the ability to repay the loan on time, so it issued the consumer credit to A. Self-employed B wanted to apply 5-year 1 million RMB consumer credit from the bank $\mathrm{D}$ for purchasing a shop. The latest income for B is about 300,000 RMB. D Bank thought although B' s current income was high, the uncertainty for his future income was high. And B is not the local resident, he does not have physical mortgage and cannot get guarantee from a third party. Bank D rejected the application from $B$. A chairman of the private enterprise $W$ applied for a one-year unspecified use of personal consumer credit from $\mathrm{E}$ Bank to purchase shares. The bank did not only assess the profitability of the enterprise, but also asked the chairman to provide full secured asset, otherwise the bank would refuse the loan to him. Doctor C needed to buy a house which is worth 1.5 million RMB, he applied 1 million loan from the bank E. Because C's annual income is about 200,000 RMB and his income is stable, the bank E agreed C's application. Through the analysis of the above cases, the results can be summarized as follows: although the growth prospects of expected income for the self-employed B are optimistic, the uncertainty is high. And W's income is affected by the company's performance. So the premise of issuing the loan from the banks is the stability of customers' income. Due to the immature risk management system in the traditional Chinese commercial banks, based on the principle of prudent operation, the Chinese commercial banks are more inclined to issue the consumer credit to the loan applicants with stable income, whose income growth expectations is small but real income is stable. The change of real income for this kind of clients' is not big, the future long-term income has higher predictability, and the repayment is guaranteed. In a word, in the process of issuing consumer credit, commercial bank's focus is the stability of the expected income.

By using the least squares linear regression model, Augmented Dickey-Fuller (ADF) unit root test, cointegration test and Granger causality test, the interactive relationship between consumer credit and expected income of urban residents in China are analyzed.

The paper uses ADF test to check out the stationarity of time series, the test equation is:

$$
\Delta \mathrm{Y}_{\mathrm{t}}=\gamma \mathrm{Y}_{\mathrm{t}-1}+\xi_{1} \Delta \mathrm{Y}_{\mathrm{t}-1}+\xi_{2} \Delta \mathrm{Y}_{\mathrm{t}-2}+\ldots+\xi_{\mathrm{p}-1} \Delta \mathrm{Y}_{\mathrm{t}-\mathrm{p}+1+\varepsilon_{\mathrm{t}}}
$$

Compare the $\mathrm{t}$ statistic to a critical value at a significant level of $1 \%, 5 \%$, and $10 \%$ to determine whether the unit has a unit root. If there is a unit root, the corresponding variables need to be differentiated in order to become stationary time series.

Although some time series themselves are non-stationary, but their linear combination is stable. This linear combination reflects the long-term co-integration relationship between the variables. The error correction model is established according to the judgment of cointegration relation. If there is a co-integration relationship between $x_{t}$ and $y_{t}$, then the residual of difference is a serially correlated moving average time series. The model can only expresses the short-term relationship between the two variables. From the perspective of long-term equilibrium, the change of the dependent variable in the period $t$ does not only depend on the change of the independent variable itself, but also depends on the state of the independent variable and the dependent variable at the end of period t-1. According to Engle-Granger two-step method, the first step, to test the cointegration relationship of variables, the parameters of longterm equilibrium relationship are estimated; the second step is to add the long-term equilibrium relation' $\mathrm{s}$ unbalanced error term into the error correction model, and using the ordinary least squares method (OLS) to estimate the corresponding parameters. Because the two variables in the real economy are rarely in equilibrium, the actual observation is only a short-term or disequilibrium relationship between the two variables. Therefore, according to the judgment of co-integration relationship, it is assumed that there is a $(1,1)$ order distributed lag relation between two variables:

$$
Y_{t}=\beta_{0}+\beta_{1} X_{t}+\beta_{2} X_{t-1}+\mu Y_{t-1}+\varepsilon_{t}
$$


Because the variable may be non-stationary, it is properly deformed:

$$
\Delta Y_{t}=\beta_{1} \Delta X_{t}-(1-\mu)\left(Y_{t-1}-\frac{\beta_{0}}{1-\mu}-\frac{\beta_{1}+\beta_{2}}{1-\mu} X_{t-1}\right)+\varepsilon_{t}
$$

Assume the long-run equilibrium relationship between the two variables is:

$$
Y_{t}=\alpha_{0}+\alpha_{1} X_{t}+\mu_{t}
$$

According to (1) and (2):

$\Delta Y_{t}=\beta_{1} \Delta X_{t}-\lambda\left(Y_{t-1}-\alpha_{0}-\alpha_{1} X_{t-1}\right)+\varepsilon_{t}$

The following coefficients can be got:

$\lambda=1-\mu$

$\alpha_{0}=\beta_{0} /(1-\mu)$

$\alpha_{1}=\left(\beta_{1}+\beta_{2}\right) /(1-\mu)$

Therefore, the long-term elasticity is $\alpha_{1}$, the short-term elasticity is $\beta_{1}$ and the error correction coefficient $\lambda$ are obtained.

Under the prerequisites that the time series must be stationary, the Granger causality test can be used to predict and analyze the causal relationship between economic variables. The test requires to estimate the following regression:

$$
\begin{aligned}
& y_{t}=\sum_{i=1}^{q} \alpha_{i X t}-i+\sum_{j=1}^{q} \beta_{j y t}-j+\mu_{1 t} \\
& X t=\sum_{i=1}^{S} \lambda_{i X t}-i+\sum_{j=1}^{S} \delta_{j} y_{t}-j+\mu 2 t
\end{aligned}
$$

Where $\mu_{1 t}$ and $\mu_{2 t}$ are assumed to be irrelevant. Equation (3) assumes that the current $\boldsymbol{y}$ is related to the past value of $y$ and $x$. Equation (4) also makes a similar assumption for the current $x$.

For (3), the null hypothesis $\mathrm{H}_{0}$ :

$\alpha_{1}=\alpha_{2}=\cdots=\alpha_{q}=0$

For (4), the null hypothesis $\mathrm{H}_{0}$ :

$\delta_{1}=\delta_{2}=\cdots=\delta_{s}=0$

If the coefficient of $x$ in (3) is not zero with statistically significance in the whole, while $y$ in (4) is zero with statistically significance in the whole, it is called the ${ }^{x}$ is the cause that induce the change of $y$.

\section{DATA DESCRIPTION}

This paper collects the data of per capita disposable income of urban households during the period of 2000 2015 through the database of China Economic and Social Development Statistics, and the number of RMB consumer credit in financial institutions in the period of $2000-2015$ s through the official website of the People's Bank of China. The growth of consumer credit and expected income are shown as figure 1 .

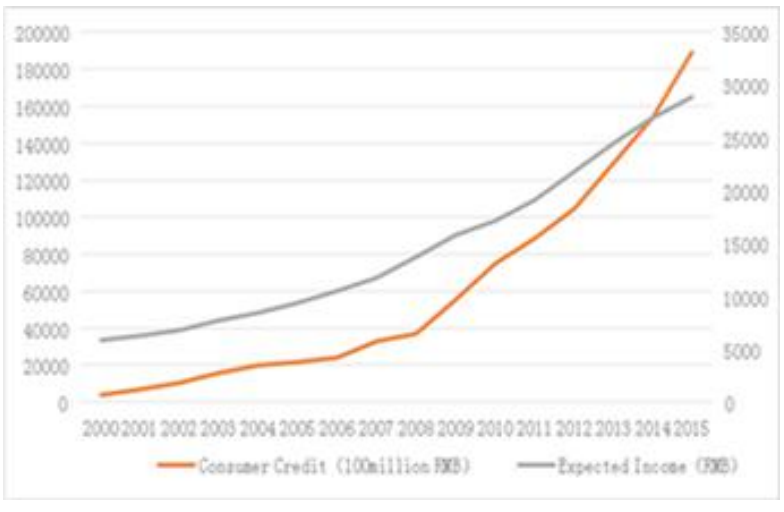

Figure 1. Growth of consumer credit and expected income

In 2000 - 2015, China's total number of consumption loans was presented as the curve-type growth. From 2000 to 2006, the amount of consumer credit in China increased from 426.5 billion RMB to 248.9 billion RMB. However, in 2005 and 2006, the growth of consumer credit was slow. The government strengthened the control on real estate during this period. Since 2007, consumer credit rapidly developed. After China fully opened the RMB business to foreign banks, the scale and types of Chinese consumer credit expanded. Banks increased credit card business. In addition, the state carry out the macroeconomic policies to actively stimulate the consumption and the effective demand, and repeatedly cut interest rates, these provide a more relaxed external political environment for commercial banks to expand consumer credit business.

The growth of per capital disposable income was slow from 2000 to 2005, and the growth rate has increased since 2006. The Chinese government has vigorously implemented the reform of income distribution, social security and medical health. From 2010, the government has gradually increased the income of low-income urban residents and civil servant, some areas implemented the standard subsidy system, the enterprise increased staff's salaries and bonuses. However, in 2014 the growth rate of per capita disposable income of urban residents declined to $7.01 \%$. The reason are the price level was high, the obvious inflation affected the residents' actual purchasing power.

The figure 1 shows that the trend of change in the RMB consumer credit is same as the trend of development in the per capita disposable income of urban households.

This paper chooses the following indicators: financial institutions' RMB consumption loans (LOAN) represents consumer credit; the current per capita disposable income of urban households (INCOME) represents the next period of urban residents' expected income. The sample characteristics of data are presented as table 1. 
TABLE I. SAMPLE CHARACTERISTICS OF DATA

\begin{tabular}{|l|c|c|}
\hline & $\begin{array}{c}\text { LOAN } \\
\text { (100million RMB) }\end{array}$ & $\begin{array}{c}\text { INCOME } \\
(\text { RMB })\end{array}$ \\
\hline Mean & 60631 & 16263 \\
\hline Median & 34970 & 14784 \\
\hline $\begin{array}{l}\text { Standard } \\
\text { deviation }\end{array}$ & 55876 & 32140 \\
\hline $\begin{array}{l}\text { Growth } \\
\text { Rate(\%) }\end{array}$ & 40.61 & 11.06 \\
\hline
\end{tabular}

\section{DATA ANALYSIS}

\section{A. ADF unit root test}

In order to eliminate the influence of heteroscedasticity, the data takes the logarithm of LOAN and INCOME, denoted as LNINCOME and LNLOAN. By doing the ADF test to verify the stationarity of variables LNLOAN, LNINCOME, D(LNLOAN) and D(LNINCOME). Only the variables can be verified stationary with same lags, the cointegration test can be done further.

TABLE II. ADF UNIT ROOT TEST OF VARIABLES

\begin{tabular}{|c|c|c|c|c|c|c|}
\hline Variable & $\begin{array}{c}\text { ADF } \\
\text { statistic }\end{array}$ & $1 \%$ level & $5 \%$ level & $10 \%$ level & Prob. & $\begin{array}{c}\text { Stationarity } \\
\text { conclusion }\end{array}$ \\
\hline$L N L O A N$ & -2.554495 & -3.959148 & -3.081182 & -2.681330 & 0.1234 & Nonstationarity \\
\hline LNINCOME & 0.252271 & -3.929148 & -3.081002 & -2.681330 & 0.9665 & Nonstationarity \\
\hline$D(L N L O A N)$ & -3.840186 & -4.004425 & -3.098896 & -2.690439 & 0.0424 & Stationarity \\
\hline$D(L N I N C O M E)$ & -3.999350 & -4.057910 & -3.119910 & -2.701103 & 0.0412 & Stationarity \\
\hline
\end{tabular}
steady under the 5\%,10\% confidence level. Each variable is a first-order sequence at a confidence level of 5\%, which satisfies the same order requirement for the co-integration test.

Through the Ordinary Linear Square method (OLS), the regression model of LNLOAN and LNINCOME is shown as follows:

\section{LNLOAN $=2.031427+0.465634$ LNINCOME \\ Adjusted $R^{2}=0.97684, \quad D W=0.710593$}

Although the adjusted R2 is 0.9768 , it is relatively high, $\mathrm{DW}=0.7106$, DW $<\mathrm{du}$, it indicates that autocorrelation exists in the model. The autocorrelation is verified by testing the unit root of regression residuals in table 3 . According to the ADF test result for the residuals, there was no cointegration relationship between expected income and consumer credit.

TABLE III. UNIT ROOT TEST OF RESIDUAL FOR ORIGINAL MODEL

\begin{tabular}{|l|c|c|c|}
\hline & t-Statistic & Prob.* \\
\hline Augmented Dickey-Fuller test statistic & -2.749591 & 0.0906 \\
\hline Test critical values: & $1 \%$ level & -4.004425 & \\
\hline & $5 \%$ level & -3.098896 & \\
\hline & $10 \%$ level & -2.690439 & \\
\hline
\end{tabular}

\section{B. Co-integration test}

Considering the stationary fist-order difference, the regression model is adjusted by adding the first-order lags of LNLOAN and LNINCOME:
The adjusted R2 is 0.9076 , it is high. All the t-statistics of the coefficients in this model are significant. $\mathrm{Du}=1.616<$ $\mathrm{DW}=2.0269<4-\mathrm{du}=2.384$, it shows that there is no autocorrelation in the model. According to the table 4, the $\mathrm{ADF}$ unit root test of the residuals in this model verified the autocorrelation has been eliminated. A long-term cointegration relationship between LNLOAN and LNINCOME can be derived.

TABLE IV. UNIT ROOT TEST FOR MODEL WITH FIRST-ORDER LAGS

\begin{tabular}{|l|c|c|c|}
\hline & t-Statistic & Prob.* \\
\hline \multicolumn{2}{|l|}{ Augmented Dickey-Fuller test statistic } & -3.453395 & 0.0000 \\
\hline Test critical values: & $1 \%$ level & -4.057910 & \\
\hline & $5 \%$ level & -3.119910 & \\
\hline & $10 \%$ level & -2.701103 & \\
\hline
\end{tabular}

The long-term elasticity can be obtained:

$$
\alpha_{1}=\frac{\beta_{2}+\beta_{z}}{1-\mu}=\frac{0.055905+0.070763}{1+0.951222}=0.064917
$$

It shows that in the long term, the expected income increase by $1 \%$, the consumer credit will increase by $0.0649 \%$.

A short-term error correction model will be constructed.

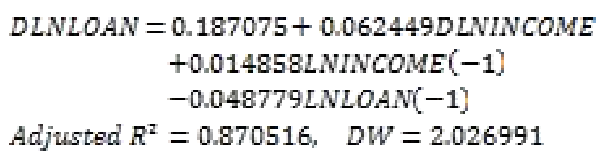


The adjusted R2 is still high, which is 0.8705. And $\mathrm{du}=1.616<\mathrm{DW}=2.026991<4-\mathrm{du}=2.384$, the model shows no autocorrelation.

According to the regression results, it was found that the short-term elasticity of the model is 0.062449 , it indicates that the expected income increase by $1 \%$ in the short term and the consumer credit will increase by $0.0624 \%$. For the fluctuations caused by exogenous shocks that result in deviations from long-run equilibrium levels, the short-term error correction coefficient is 0.048779 .

\section{Granger causality test}

According to the table 5 , in the 2 lags the probability of the expected income is not the Granger reason for consumer credit is only 0.0053 . The null hypothesis can be rejected. It indicates that the expected income is the Granger reason for consumer credit. But the consumer credit with 2 lags is not the Granger reason of the expected income. In the more than 2 lags, the test shows the same results.

It can be concluded that in the adaptive expectation the growth of the expected income of Chinese urban residents leads to an increase in the amount of consumer credit in the commercial banks.

TABLE V. GRANGER CAUSALITY TEST

\begin{tabular}{|c|c|c|}
\hline Null Hypothesis & Lags & Prob. \\
\hline LNLOAN does not Granger Cause LNINCOME & 2 & 0.6804 \\
\hline LNINCOME does not Granger Cause LNLOAN & 2 & 0.0053 \\
\hline LNLOAN does not Granger Cause LNINCOME & 3 & 0.885 \\
\hline LNINCOME does not Granger Cause LNLOAN & 3 & 0.0092 \\
\hline
\end{tabular}

\section{CONCLUSIONS}

According to the data analysis, there is a positive relationship between consumer credit and expected income of urban residents in China. In the short term, with the expected income increased by $1 \%$, the amount of consumer credit will increase by $0.0624 \%$. In the long term, with the expected income increased by $1 \%$, the amount of consumer credit will increase by $0.0649 \%$.

Based on the empirical study, two suggestions are put forward:
The income of residents should be increased and the concept of consumer credit should be updated. Measures should be taken to increase the residents' wages, laid-offs' living security and social welfare in the income policy for the income gap further narrowing. In addition, it is needed to encourage the residents to change the consumption concept and promote residents for moderate consumption on the purpose of improving their own life quality.

Consumer Credit System and relevant laws and regulations should be improved. It is important to implement a unified personal credit evaluation system and to set up professional intermediary agencies for investigation and evaluation of personal credit. The consumer credit guarantee and insurance system need to be established, even to encourage financial institutions to carry out a social consumer credit insurance mechanism that cooperated with business insurance company.

This paper only studied the relationship between consumer credit and the expected income of Chinese urban residents. It does not consider the influence of other macroeconomic factors. The future research can add the price level, savings and personal income tax.

\section{REFERENCES}

[1] A.F. Andrade, and L. Thomas, "Structural models in consumer credit,", Science Direct: European Journal of Operational Research. vol. 183, 2007, pp. 69-70.

[2] K. Beaton, "Credit Constains and Consumer Spending," Bank of Canada Working Paper, 2009.

[3] S.S. Ba, and X.H. Chen, "Financial system under the rapid expansion of consumer credit," Western Forum, vol. 11, 2004, pp. 45-47.

[4] H. Guo, and W.M.. Zhou, "Individual Consumer Credit Sino-Us Comparison and Experience," Financial Forum, vol. 8, 2007, pp. 1728.

[5] X. Guo, and W. Liu, "Analysis of influencing factors of consumer credit decision," Learning and Exploration, vol. 3, 2010, pp 159-161.

[6] B. Hang, and C. Shen, "Analysis on consumption of urban residents in China," Economic Research, vol. 9, 2004.

[7] L. Lu, "Liquidity shocks, macroeconomic regulation and management," Administrative Reform, vol. 11, 2015, pp. 24-25.

[8] D.K. Maston, and S.S. Nicholas, "A portfolio view of consumer credit," Journal of Monetary Economics, vol. 2, 2006, pp. 59-84.

[9] L. Qian, "Factor decomposition of income gap between urban and rural residents -- Based on individual characteristics of workers," Economy, vol. 27, 2015, pp 1-5.

[10] H. Wang, "Enlightenment of Keynes's theory of effective demand of economic for Chinese," Enterprise Culture Management, No. 6, 2015. 